\title{
Obstructing calculus in a single limb of a duplicated ureter: A Recall of the surgical anatomy and the Variable Ureter Anomalies
}

Shawish $\mathrm{FA}^{1}$, Shawish $\mathrm{WA}^{2}$

${ }^{1}$ Department of Urology, Dr Suleiman al habib Hospital, Dubai, United Arab Emirates

${ }^{2}$ Monash medical center, Melbourne, Victoria, Australia

Corresponding Author: Fahmy Abu Shawish MS, FRCS

Address: Department of Urology, Dr Suleiman al habib Hospital, Dubai, United Arab Emirates; E-mail: doctorfahmy@gmail.com

Received date: 29 August 2019; Accepted date: 04 September 2019; Published date: 10 September 2019

Citation: Shawish FA, Shawish WA. Obstructing calculus in a single limb of a duplicated ureter: A Recall of the surgical anatomy and the Variable Ureter Anomalies. Asp Biomed Clin Case Rep. 2019 Sept 10;2(2):30-33.

Copyright (C) 2019 Shawish FA, Shawish WA. This is an open-access article distributed under the Creative Commons Attribution License, which permits unrestricted use, distribution, and reproduction in any medium, provided the original work is properly cited.

\begin{abstract}
The ureter is a common site of congenital anomalies which may be associated with a considerable morbidity particularly among young patient. The congenital anomalies of the ureter coexist with multitude of other urinary tract anomalies but it may occur independently. It is more common in females. The complete duplication of the ureter may not produce symptoms which would suggest the presence of malformation. Therefore, such anomaly may not become apparent until later in life. Further, this anomaly might not be recognized prior to the surgery and hence, missing of the stone is highly possible.
\end{abstract}

Herein we present a case of complete ureter duplicate with an obstructive stone located close to VUJ of one limb of the duplicate. A sound knowledge of the surgical anatomy and of the congenital ureter anomalies is essential for correct diagnosis and appropriate management.

\section{Keywords}

Duplicated Ureter(DU); Unenhanced CT KUB; Vesico-ureteric Junction(VUJ); Ultrasonography; Ureteroscopy(URS); Calculus

\section{Introduction}

The ureter is a derivative of the wolffian (mesonephric) duct. Ureteral bud branches off from the caudal portion of Wolffian duct at the fourth and fifth week of gestation. Alteration in the bud number, position or time of development results in ureteral anomalies. A combination of genetic mutation and environmental factors contribute to the formation of urinary tract anomalies [1,2].Ureter duplication is inherited by an autosomal dominant gene of variable penetration [3]. The highest prevalence has been reported in Caucasian females [4,5]. Duplication of the ureter may be incomplete (bifid ureter) or complete in which each limb of the duplicate open separately in the bladder and this is a rare anomaly $[6,7]$.The VUJ orifice of the limb which drain the upper renal moiety (the first limb of the duplicate) has ectopic insertion usually medial and inferior to the lower pole moiety ureter (the second limb of the duplicate) which has orthotopic insertion in the bladder (Weigert-Mayer law) [1]. The complete duplication is present in approximately in 1 from 125 individual [6].It is more common in females than males with a ratio of 2:1 [5].In the English literature few cases of calculi found in one limb or in the two limbs of the duplicated ureter $[8,9]$. More few cases reported with bilateral 
Citation: Shawish FA, Shawish WA. Obstructing calculus in a single limb of a duplicated ureter: A Recall of the surgical anatomy and the Variable Ureter Anomalies. Asp Biomed Clin Case Rep. 2019 Sept 10;2(2):30-33.

ureteric duplication in which stones were found in all of the limbs of the duplicate [10]. Some cases of ureteral duplication with ureterocele stone have been reported $[5,7]$.A similar cases of duplex were also detected in a research study and another seen during a routine dissection of a cadaver $[6,11]$. Generally speaking most of the aberrations detected incidentally during URS surgery for obstructing stone or during other pelvic organ surgery [5]. Herewith we present an additional case of complete duplicated left ureter with an impacted calculus found in a single limb of the duplicate. Meanwhile some related elegant images selected from many others are also presented.

\section{Case Presentation}

A 22year old female patient in the last month she repeatedly attended the emergency room (ER) with a complaint of left sided abdominal pain, dysuria and difficulty in urine void. Her abdomen was mildly tender on the left iliac fossa. She had microscopic hematuria with few RBC's seen in her sterile urine. Urine pregnancy test was negative. Blood work including kidney profile was all normal. Ultrasound scan revealed obstructive $7.8 \mathrm{~mm}$ calculus close to the anatomical site of left VUJ (Fig-1). Subsequent plain

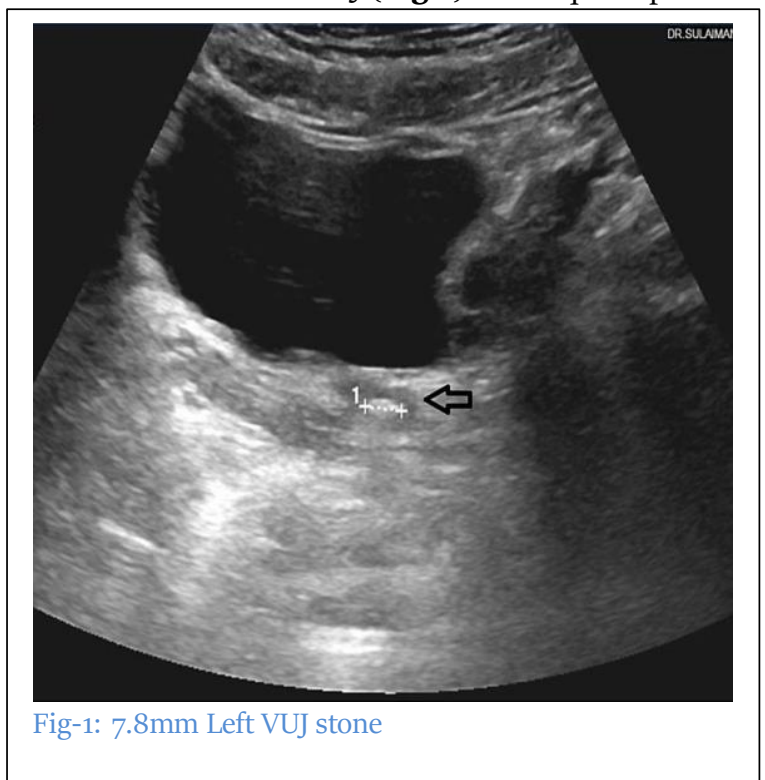

CT KUB scan emphasize the presence of the calculus impacted at the same described location. In addition a bilateral non obstructive tiny renal gravels $(3-4 \mathrm{~mm}$ each) were also seen (Fig-2). Subsequently left ureteroscopy was suggested; therefore informed written consent was taken. Her bowel evacuated with low rectal enema. Eventually smooth rigid left ureteroscopy was done through the normally appearing left VUJ orifice. Surprisingly the previously described stone was not seen in the scoped limb of the duplicated ureter and considered as missing. This

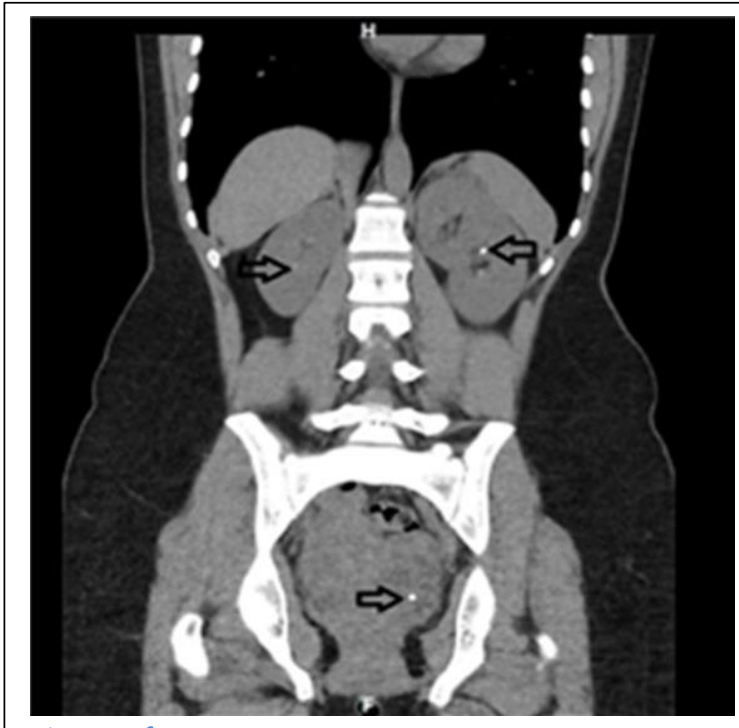

Fig-2: Left VUJ 7.8mm stone

raised a high index of suspicion for ureteric anomaly. Therefore, a thorough cystoscopy guided us to a pinpoint, with small caliper, congested and edematous another orifice $1 \mathrm{~cm}$ inferior and medial to the normally located orifice (weigert- Mayer law applies) (Fig-3). This second left VUJ orifice was poorly

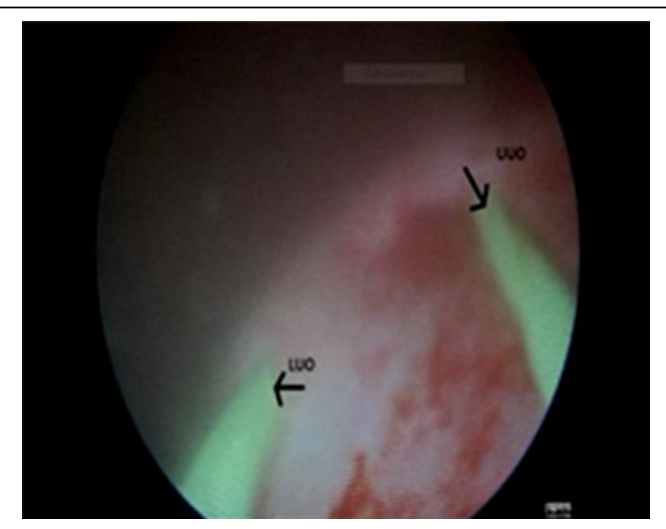

Fig-3: LUO Left lower ureteric orifice

UUO Left upper ureteric orifice with separate guide wire in

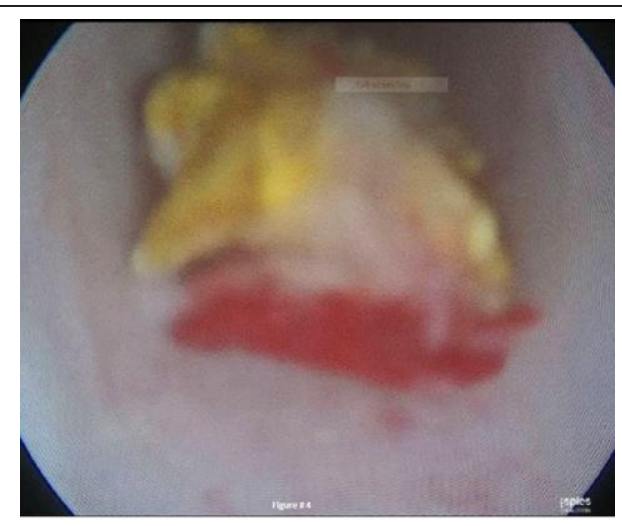

Fig-4: 7.8mm stone at VUJ of one limb of duplicated left ureter 
compliant and negotiated with difficulty. Ultimately it led us to the second limb of the duplicated left ureter with an impacted stone encountered inside and just close to the ureteric orifice of this limb (Fig-4).The calculus broken with holmium laser and the fragments were removed with complete clearance. The two limbs stented separately with a ureteric catheter $\mathrm{F}_{5}$ for a day (Fig-5).The recovery was uneventful. The catheters were removed next day and she discharged after spontaneous void.

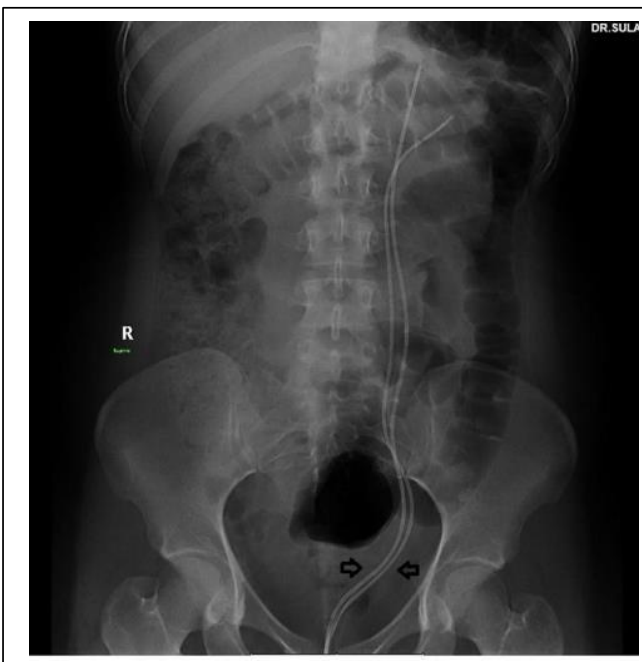

Fig-5: Two ureteric catheters $\mathrm{F}_{5}$ in each limb of duplicated left ureter

\section{Discussion}

Ureteral duplication usually is asymptomatic and its diagnosis is incidental. It can be associated with urinary tract infection, vesicoureteric reflux, ureterocele, stone formation, obstructive uropathy, ectopic ureter and other congenital complications $[3,5,7]$. In such cases renal morphology, ureteral condition and renal function warranted to be evaluated.The initial evaluation of a patient with a suspected obstructive stone usually occur in the emergency room (ER). As a gold standard in the clinical practice currently this is limited to unenhanced CT KUB scan [12]. However CT scan is associated with hazards of radiation and high cost [12]. Nevertheless American Urological Association (AUA) and American College of Radiology (ACR), recommends the non-contrast CT KUB scan as a first line investigation for all of the adult patients presenting with symptoms suggesting of obstructive stones [13]. It has the highest sensitivity (94-97\%) and the highest specificity (96-100\%) and consistently provide the most accurate diagnosis
$[12,13]$. In addition Hounsfield unit can be measured if ESWL is considered [7,14]. On the other side European Association of Urology (EAU) differ regarding the optimal initial imaging modal, considering the ultrasound KUB scan as the first line of investigation for similar conditions [13]. Ultrasound scan has $40 \%$ sensitivity and $84 \%$ specificity [12]. However all the main guide line providers (AUA, ACR and EAU) agreed on the ultrasound KUB scan to be the first line of investigation in pregnant women and pediatric patients [13].Currently the sensitivity and specificity of standard KUB radiography estimated to be $57 \%$ and $76 \%$ respectively [13]. In a combined study for ultrasound scan and KUB radiography a wide variation exist in the sensitivity and specificity. It estimates the combined sensitivity and specificity with 58\%-100\% and 37\%-100\% respectively [13]. However none of the main bodies providing guidance recommend the contrast material to be used as a first line investigation in a patient with obstructive ureteric stones. Therefore the surgical anatomy of the aberrant ureter without contrast may not be visualized and hence any duplication of the ureter mostly will not be illustrated prior to the surgical procedure. So, in most of the patients with impacted ureteric stone of the duplicated ureter, similar to our case, most of the anomalies can be detected only in the theater during the procedure of ureteroscopic stone extraction. In such cases there is a high possibility for the ureteric anomaly to be missed and hence the calculus will not to be accessed [8]. Indeed in our search in the English medical literature many of the treated patients of the impacted calculus in a duplicated ureter in a single limb or in both limbs patient required a subsequent definitive further treatment $[7,8,10]$. Usually this may prolong the hospital stay and consequently increase the cost of treatment. Further it may subject the patient to a possible but avoidable complication. Therefore a solid knowledge of the surgical anatomy and the awareness of the congenital ureteric anomaly particularly with complete duplicated ureter might change the pitfall to a successful surgery with stone removal and in a single session [15]. 


\section{Conclusion}

Recall of the congenital anomalies of a duplicated ureter prior to the surgery of an obstructing calculus is crucial to reduce both morbidity rate and the cost of the treatment.

\section{Aknowledegment}

Alina Shahid, SN, Dr Sulaiman al habib hospital. For her input in collecting the patients data.

\section{References}

[1] Mittal MK, Sureka B, Mittal A, Sinha M, Thukral BB, Mehta V. Congenital Anomalies of Kidney and Ureter. Anat Physiol. 2016 Dec 29;6:19o.

[2] Capone VP, Morello W, Taroni F, Montini G. Genetics of Congenital Anomalies of the Kidney and Urinary Tract: The Current State of Play. Int J Mol Sci. 2017 Apr 11;18(4). pii: E796. [PMID: 28398236] [3] Atwell JD, Cook PL, Howell CJ, Hyde I, Parker BC. Familial incidence of bifid and double ureters. Arch Dis Child. 1974 May;49(5):390-3. [PMID: 4834020]

[4] Scantling D, Ross C, Altman H. A 52-year-old male with bilaterally duplicated collecting systems with obstructing ureteral stones: a case report. Curr Urol. 2013 Nov;7(2):104-6. [PMID: 24917767]

[5] Varlatzidou A, Zarokosta M, Nikou E, Theodoropoulos P, Kakaviatos D, Piperos T, Kalles V, Bonatsos V, Mariolis-Sapsakos T. Complete unilateral ureteral duplication encountered during intersphincteric resection for low rectal cancer. J Surg Case Rep. 2018 Oct 11;2018(10):rjy266. [PMID: 30323916]

[6] Dinanath P, Ashwini A, Annarao G, Nagaraj S. Bilateral complete duplex renal pelves and ureters a case report. Int J Anat Var. 2011 Dec 13;4:192-94.

[7] Abdi H, Kaseb K, Rezaee H, Moradi M. Unilateral complete ureteral duplication with calculi obstructing both limbs of the left side. Urol Case Rep. 2018 Mar 31;18:91-93. [PMID: 29785384]

[8] Nyanhongo DK, Antil S, Nasir S. Pitfalls of the duplex system: the mystery of the missing stone. BMJ Case Rep. 2017 Jun 13;2017. pii: bcr-2017220198. [PMID: 28611171]

[9] Aiken WD, Johnson PB, Mayhew RG. Bilateral complete ureteral duplication with calculi obstructing both limbs of left double ureter. Int J Surg Case Rep. 2015;6C:23-5. [PMID: 25506845]

[10] Migliari R, Usai E. Ureteroscopic removal of ureteral calculi in bilateral ureteral duplications. Urol Int. 1991;46(1):79-81. [PMID: 2024381]

[11] Tang MJ, Arachchi A, Mehdipour R, Mataj A, Briggs C. Unilateral duplex ureter. Int J Anat Var. 2018 Apr 16;11(2):51-52.

[12] Vijayakumar M, Ganpule A, Singh A, Sabnis R, Desai M. Review of techniques for ultrasonic determination of kidney stone size. Res Rep Urol. 2018 Aug 10;10:57-61. [PMID: 30128307]

[13] Brisbane W, Bailey MR, Sorensen MD. An overview of kidney stone imaging techniques. Nat Rev Urol. 2016 Nov;13(11):654-662. [PMID: 27578040]

[14] Alsayyad AJ. Bilateral complete duplication of the ureters, with calculi simultaneously obstructing the four ureters. Urol Ann. 2016 Apr-Jun;8(2):22628. [PMID: 27141198]

[15] Karakose A, Aydogdu O, Atesci YZ. Unilateral complete ureteral duplication with distal ureteral stone: A rare entity. Can Urol Assoc J. 2013 JulAug;7(7-8):E511-2. [PMID: 23914272]

Keywords: Duplicated Ureter(DU); Unenhanced CT KUB; Vesico-ureteric Junction(VUJ); Ultrasonography; Ureteroscopy(URS); Calculus 